\title{
Effect of caudal epidural steroid or saline injection in chronic lumbar radiculopathy: multicentre, blinded, randomised controlled trial
}

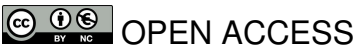

\author{
Trond Iversen consultant ${ }^{15}$, Tore K Solberg consultant ${ }^{23}$, Bertil Romner professor ${ }^{4}$, Tom Wilsgaard \\ assistant professor ${ }^{5}$, Jos Twisk professor ${ }^{6}$, Audny Anke assistant professor ${ }^{17}$, Øystein Nygaard \\ professor $^{38}$, Toralf Hasvold professor ${ }^{5}$, Tor Ingebrigtsen professor ${ }^{7}$
}

\begin{abstract}
${ }^{1}$ Department of Rehabilitation, University Hospital of North Norway, 9038 Troms $ø$, Norway; ${ }^{2}$ Department of Neurosurgery, University Hospital of North Norway; ${ }^{3}$ Norwegian Registry for Spine Surgery, North Norway Regional Health Authority, Troms $\varnothing ;{ }^{4}$ Neuroscience Centre, Department of Neurosurgery, Rigshospitalet, Copenhagen, Denmark; ${ }^{5}$ Faculty of Health Sciences, Department of Community Medicine, University of Troms $\varnothing$, Tromsø; ${ }^{6} \mathrm{VU}$ University Medical Centre, Amsterdam, Netherlands; ${ }^{7}$ Faculty of Health Sciences, Institute of Clinical Medicine, Troms $\varnothing ;{ }^{8}$ Department
\end{abstract} of Neuroscience, Norwegian University of Science and Technology, Trondheim, Norway

\begin{abstract}
Objective To assess the efficacy of caudal epidural steroid or saline injection in chronic lumbar radiculopathy in the short (6 weeks), intermediate (12 weeks), and long term (52 weeks).

Design Multicentre, blinded, randomised controlled trial.

Setting Outpatient multidisciplinary back clinics of five Norwegian hospitals.
\end{abstract}

Participants Between October 2005 and February 2009, 461 patients assessed for inclusion (presenting with lumbar radiculopathy $>12$ weeks). 328 patients excluded for cauda equina syndrome, severe paresis, severe pain, previous spinal injection or surgery, deformity, pregnancy, ongoing breast feeding, warfarin therapy, ongoing treatment with non-steroidal anti-inflammatory drugs, body mass index $>30$, poorly controlled psychiatric conditions with possible secondary gain, and severe comorbidity.

Interventions Subcutaneous sham injections of $2 \mathrm{~mL} 0.9 \%$ saline, caudal epidural injections of $30 \mathrm{~mL} 0.9 \%$ saline, and caudal epidural injections of $40 \mathrm{mg}$ triamcinolone acetonide in $29 \mathrm{~mL} 0.9 \%$ saline. Participants received two injections with a two week interval.

Main outcome measures Primary: Oswestry disability index scores. Secondary: European quality of life measure, visual analogue scale scores for low back pain and for leg pain.

Results Power calculations required the inclusion of 41 patients per group. We did not allocate 17 of 133 eligible patients because their symptoms improved before randomisation. All groups improved after the interventions, but we found no statistical or clinical differences between the groups over time. For the sham group $(n=40)$, estimated change in the Oswestry disability index from the adjusted baseline value was -4.7 (95\% confidence intervals -0.6 to -8.8$)$ at 6 weeks, -11.4
(-6.3 to -14.5$)$ at 12 weeks, and $-14.3(-10.0$ to -18.7$)$ at 52 weeks. For the epidural saline intervention group $(n=39)$ compared with the sham group, differences in primary outcome were $-0.5(-6.3$ to 5.4$)$ at 6 weeks, 1.4 (-4.5 to 7.2$)$ at 12 weeks, and $-1.9(-8.0$ to 4.3$)$ at 52 weeks; for the epidural steroid group $(n=37)$, corresponding differences were -2.9 ( -8.7 to 3.0$), 4.0$ (-1.9 to 9.9), and 1.9 (-4.2 to 8.0). Analysis adjusted for duration of leg pain, back pain, and sick leave did not change this trend.

Conclusions Caudal epidural steroid or saline injections are not recommended for chronic lumbar radiculopathy.

Trial registration Current Controlled Trials ISRCTN No 12574253.

\section{Introduction}

Chronic lumbar radiculopathy is defined as a clinical syndrome of back and leg pain accompanied by sensory, reflex, or motor deficits in a nerve root distribution lasting for more than 12 weeks. ${ }^{1-4}$ The lifetime prevalence of lumbar radiculopathy has been reported to be $5.3 \%$ in men and $3.7 \%$ in women. ${ }^{56}$ Lumbar radiculopathy due to a prolapsed disc resolves spontaneously in $23-48 \%$ of patients, but up to $30 \%$ will still have pronounced symptoms after one year, $20 \%$ will be out of work, and 5-15\% will undergo surgery. ${ }^{7-10}$

Epidural steroid injections for lumbar radiculopathy have been used since 1953. ${ }^{11}$ Along with mechanical compression of nerve roots, lumbar radiculopathy can be triggered by different proinflammatory chemical agents, ${ }^{12-15}$ causing ectopic neuron firing. ${ }^{16}$ Steroids injected into the epidural space or around the affected nerve root are thought to inhibit these inflammatory mediators. However, there is conflicting evidence for a potential 
benefit of epidural steroid injections. ${ }^{17-21}$ Some studies have shown a moderate short term benefit, ${ }^{18-25}$ whereas others have shown little difference between epidural steroid and placebo injections. ${ }^{26-28}$ Studies comparing epidural steroid injections with epidural saline or local anaesthetic injections have shown less benefit from steroids ${ }^{26} 290$ than those comparing epidural steroid injections with sham or soft tissue injections. 22233132

Furthermore, recent studies have concluded that epidural local anaesthetic or saline alone could have a positive effect by itself. ${ }^{33} 34$

At the one year follow-up after epidural steroid injection, improvement of pain and disability has been reported for $36 \%$ to $43 \%$ of the patients. ${ }^{25}$ However, this outcome does not differ greatly from the natural history of the disease.$^{36}$ The true effect of epidural steroid injections might be to reduce radicular pain before natural recovery occurs. ${ }^{37}$ Despite the lack of evidence for long term efficacy, the use of epidural steroid injection in the United States increased from 553 to 2055 per 100000 patients from 1994 to $2001 .^{38}$ In the United Kingdom, epidural steroid injection for lumbar radiculopathy was one of the most common therapeutic spine injection procedures in 2002-03. ${ }^{1}$

We aimed to assess the effects of caudal epidural steroid and saline injections compared with subcutaneous sham injections in patients with chronic radiculopathy, by measuring improvements in physical function, health related quality of life, and pain at short term (6 weeks), intermediate term (12 weeks), and long term (52 weeks) follow-up.

\section{Methods}

We used a subcutaneous sham injection to control for the possible effect of a high volume saline injected into the epidural space, and we compared epidural steroid injections with epidural saline injections to clarify the effect of steroids.

\section{Participants}

We referred patients with lumbar radiculopathy from the catchment area of the University Hospital of North Norway, St Olavs University Hospital, Levanger Hospital, Nordland Hospital, and Buskerud Hospital (population 1146 076). The general practitioners, neurosurgeons, orthopaedic surgeons, neurologists, manual physiotherapists, and chiropractors working in these areas were informed by letter about the trial.

The inclusion criteria included unilateral lumbar radiculopathy lasting for more than 12 weeks. The intensity of the leg pain, radiating from the back to below the knee, had to be comparable or worse than the back pain. We assessed eligible patients aged between 20 and 60 years consecutively for inclusion and obtained written informed consent. The clinical examination followed a prepared study template to decide whether the patient had a lumbar radiculopathy and to determine the most probable nerve root affected. Trained neurologists or specialists in physical medicine and rehabilitation in cooperation with a physiotherapist undertook the inclusion examinations. We excluded 328 patients presenting with a cauda equina syndrome, severe paresis, severe pain, history of spinal injection or surgery, deformity, pregnancy, ongoing breast feeding, warfarin therapy, ongoing treatment with non-steroidal anti-inflammatory drugs, body mass index of more than 30 , poorly controlled psychiatric conditions with possible secondary gain, or severe comorbidity. Twenty four (7\%) excluded patients underwent back surgery. We did magnetic resonance imaging $(n=110)$ or computed tomography $(n=6)$ in all included patients. Experienced radiologists at each centre assessed the images and produced a written report for the investigators. Inclusion in the trial was not dependent on the results from the magnetic resonance imaging and computed tomography. The results did not have to correspond with those from the clinical examination. To be included, the patients had to have clinically proved radiculopathy. We excluded patients who showed severe intraspinal pathology (large disc herniations occupying more than $50 \%$ of the spinal canal, spinal stenosis, tumours, bleeding, dural fistula, synovial cysts, or dysraphia).

Each patient completed self administered questionnaires including the outcome measures, which were identical at baseline and follow-up. The baseline questionnaires contained additional questions about demographics, education, duration of pain, work status, avoidance of movement owing to fear of pain, medication, and lifestyle issues. We also monitored clinical signs of lumbar radiculopathy, need for physiotherapy or surgery during follow-up, whether the patient perceived benefit of the intervention, beliefs about fear avoidance, ${ }^{39}$ and working capability at each follow-up. All patients received standardised oral and written information about spine anatomy and function at baseline and follow-up. Patients were encouraged to engage in physical activity, ${ }^{40-43}$ and received an information brochure. ${ }^{44}$ Patients using non-steroidal anti-inflammatory drugs were told to stop this medical treatment.

\section{Randomisation}

The clinical research centre at the University Hospital of North Norway used a computer generated block scheme for randomisation, stratified by intervention hospital. The centre was contacted by telephone on the day of intervention. The individuals undertaking the randomisation did not take any further part in the trial.

\section{Outcomes}

The Oswestry disability index was the primary outcome measure. The Oswestry disability index questionnaire contains 10 questions on limitations of activities to daily living. Each variable was rated on a $0-5$ point scale, added up, and converted into a percentage functional score ranging from 0 to 100 (where $0=$ no disability). ${ }^{45-47}$

We assessed secondary outcome measures by the European quality of life measure, the visual analogue scale for low back pain, and the visual analogue scale for leg pain. The European quality of life measure is a generic and preference weighted measure of health related quality of life. It evaluates five dimensions: mobility, self care, activities of daily life, pain, and anxiety or depression. For each dimension, the patient describes three possible levels of problems (none, mild to moderate, and severe). This descriptive system contains 243 (35) combinations or index values for health states. ${ }^{48}$ We used the value set from the main survey of the EuroQol group, ${ }^{49}$ which has been validated for patients with lumbar radiculopathy. ${ }^{50}$ Total score range is from -0.594 to 1 , where 1 corresponds to perfect health and 0 to death. Negative values are considered to be worse than death. ${ }^{48}$ The intensity of leg pain and low back pain was indicated on a horizontal $100 \mathrm{~mm}$ visual analogue scale (where $0=$ no pain $).{ }^{50}$

\section{Follow-up}

A blinded physiotherapist and doctor followed up patients at 6 , 12 , and 52 weeks. Use of physiotherapy was recorded during follow-up, but was not routinely offered to the patients. During the study, surgeons independently assessed the need for surgical treatment among patients with increasing pain or paresis. 
We used a global question on a four point Likert scale to measure the benefit of the intervention at each follow-up. ${ }^{52}$ The patients were asked: "What benefit of the treatment have you had?" The response alternatives were: "much", "some", "no benefit", and "I am worse". We recoded these variables into a dichotomous outcome with "much" and "some" benefit representing that the patients had benefited from the treatment.

\section{Intervention}

A standardised referral letter for the intervention contained information about the patient's cardiac and pulmonary status, medication, and allergies, but did not include information about back pain and radiculopathy. There were three intervention groups. Group 1 received subcutaneous sham injections of 2 $\mathrm{mL} 0.9 \%$ saline, superficial to the sacral hiatus and not into the spinal canal. Group 2 received caudal epidural injections of 30 $\mathrm{mL} 0.9 \%$ saline. Group 3 received caudal epidural injections of $40 \mathrm{mg}$ triamcinolone acetonide in $29 \mathrm{~mL} 0.9 \%$ saline. All three intervention groups received two injections with a two week interval; the second injection was cancelled if spontaneous recovery had occurred between inclusion and the first intervention.

An experienced anaesthesiologist gave the injections and followed a set template. ${ }^{53}$ Anatomical landmarks were used to identify the sacral hiatus. In addition, use of an ultrasound machine (Honda Diagnostic Scanner HS-2000 Cine, Honda Electronics Co) capable of examining musculoskeletal tissues with a $10 \mathrm{MHz}$ real time linear array ultrasound transducer increased the precision of the injections. ${ }^{55-57}$

\section{Blinding}

We ensured that the patients, outcome assessors, and care providers were blinded during the study period; they were all unaware of the randomisation and intervention given by the anaesthesiologists. The anaesthesiologist giving the injections was not blinded because inclusion of a subcutaneous sham group made this impossible. ${ }^{58}$ The injection products were concealed from the patients, and the anaesthesiologists were instructed not to discuss the injection procedure or the products used with the patients.

\section{Statistical analysis}

We did sample size calculations for a multicentre multilevel longitudinal model with repeated measurements on the primary continuous outcome variable, the Oswestry disability index. The study was powered to detect an assumed clinically significant difference between one of the two injection groups and the sham group of 10 points on average over time. Based on a standard deviation of 18 , a significance level of $5 \%$, a power of $80 \%$, and a correlation coefficient of 0.6 between the three follow-up measurements, the number of patients in each intervention group needed to be 37 . Adjusting for losses to follow-up and withdrawals from the study, we set the minimum number of patients to be included in each group to be 41 .

The analyses for all outcome measures used all available data on an intention to treat basis. We analysed all patients according to the group to which they were allocated, regardless of crossovers, surgery, withdrawal from the study, or loss to follow-up. In the analysis of outcomes in patients who withdrew or were lost to follow-up, we used the available data in the mixed model analysis. We analysed data with Stata 11.0 (StataCorp) and SPSS 17.0 (SPSS Inc). percentages. We assessed groups at baseline by analysis of variance for continuous variables and by Pearson $\chi^{2}$ tests for categorical variables.

We used linear mixed models to assess differences in time trends between the treatment groups for the primary and secondary outcome measures. ${ }^{59}$ We added time to the model as a categorical variable represented by dummy variables to analyse the differences between the groups at different time points. In all mixed model analyses, we made a crude adjustment for the baseline values of the particular outcome variable. In secondary analysis, we made additional adjustments for any duration of back pain, leg pain, and sick leave before inclusion. All tests were two sided using a significance level of $5 \%$.

\section{Results}

Between October 2005 and February 2009, 461 patients were assessed for inclusion, and 133 were included in the study (48, University Hospital of North Norway; 20, Nordland Hospital; 26, Levanger Hospital; 27, St Olavs University Hospital; 12, Buskerud Hospital). Of the 328 excluded patients, three exclusions (1\%) were because of intraspinal pathology and eight (2\%) because of psychiatric conditions. Seventeen patients did not undergo randomisation because their symptoms improved between assessment and randomisation (fig $1 \Downarrow$ ). Therefore, we included $116(25 \%)$ patients in the intention to treat analysis.

After randomisation, we excluded another five patients because of spontaneous improvement before the first injection (fig 1). We analysed 37 patients in the caudal epidural steroid group, 39 in the caudal epidural saline group, and 40 in the sham group (fig 1). We followed up 109 patients at 6 weeks, 105 at 12 weeks, and 99 at 52 weeks (table $1 \Downarrow$ ). We did not record any crossovers between the treatment groups. The distribution between treatment groups within each hospital was roughly equal, and adjustment for hospital did not change these results (table $2 \Downarrow$ ). Table $3 \Downarrow$ shows baseline characteristics of the study population. We did not detect any significant differences between treatment groups, except for a significantly higher rate of the presence of ankle tendon reflex difference among patients in the caudal epidural saline group.

The median interval between inclusion and randomisation to the first injection was 3 (range $0-17$ ) weeks, and the median interval between the two injections was 3 (2-5) weeks. This variation was caused by logistical and patient related factors affected by long travelling distance in rural Norway. We did not detect any difference in median time interval between inclusion and randomisation between the groups. We registered no serious complications from the injections. Six $(5 \%)$ patients experienced local pain during the first injection and declined the second injection, thereby discontinuing the intervention (fig 1). The treatment groups did not differ significantly for the primary and secondary outcomes. Figures $2-5 \Downarrow \Downarrow \Downarrow \Downarrow$ show the between group differences for the primary and secondary outcome variables from baseline to follow-up.

For both the primary and secondary outcome measures at 6,12 , and 52 week follow-up, we did not see any significant differences between the epidural injection groups and the sham group. Furthermore, the observed differences were not clinically important. ${ }^{60}$ The estimated change in the Oswestry disability index from the adjusted baseline value for the sham group was -4.7 (95\% confidence intervals -0.6 to -8.8$)$ at 6 week follow-up, $-11.4(-6.3$ to -14.5$)$ at 12 weeks, and $-14.3(-10.0$ to -18.7$)$ at 52 weeks. The observed between group differences at 6,12 , and 52 week follow-up between the epidural injection groups and the sham group were not clinically important. These 
results did not change after we adjusted for both the baseline scores and the duration of leg pain, low back pain, and sick leave (tables $4 \Downarrow$ and $5 \Downarrow$ ).

\section{Ancillary analysis}

Fear avoidance belief scores decreased significantly from baseline to the 52 week follow-up in all three groups $(\mathrm{P}<0.001)$ but did not differ significantly between the groups (table $6 \Downarrow$ ). We did not find a significant reduction in the use of pain relief medication from baseline to the 6 week follow-up, nor did we record any significant difference between the intervention groups in the use of paracetamol $(\mathrm{P}=0.26)$, non-steroidal anti-inflammatory drugs $(\mathrm{P}=0.45)$, or morphine $(\mathrm{P}=0.70)$ (table $7 \Downarrow)$.

Between baseline and 52 week follow-up, we detected a significant reduction in patients receiving sickness benefit in the sham group $(\mathrm{P}=0.01)$ but not in either of the epidural injection groups. However, there were no significant differences between the groups $(\mathrm{P}=0.61)$. At the 52 week follow-up, 28 (28\%) patients received sickness benefit: $7(22 \%)$ in the sham group, $10(30 \%)$ in the epidural saline group, and 11 (32\%) in the epidural steroid group.

During follow-up, 41 (13\%) patients had physiotherapy: 12 $(11 \%)$ at 6 weeks, $18(17 \%)$ at 12 weeks, and $11(11 \%)$ at 52 weeks, with no significant differences between the groups $(\mathrm{P}=0.69)$. Fifteen $(15 \%)$ patients had back surgery at the 52 week follow-up: one (1\%) in the epidural steroid group, six $(6 \%)$ in the epidural saline group, and eight (8\%) in the sham group, with no significant differences between the groups $(\mathrm{P}=0.07)$.

At baseline, all patients had clinically verified lumbar radiculopathy (table 1). At 52 week follow-up, 27 (27\%) patients still had a lumbar radiculopathy, with no significant differences seen between the groups $(\mathrm{P}=0.95)$. At 52 week follow-up, 49 $(50 \%)$ patients stated that they had received "much" or "some" benefit from the treatment, with no significant differences seen between the groups $(\mathrm{P}=0.81)$.

\section{Discussion}

This randomised controlled trial compared caudal epidural steroid or saline injections with subcutaneous sham injections. The results confirm the null hypothesis that treatment of chronic lumbar radiculopathy with caudal epidural injection of steroids or isotonic saline has no clinically important effect. We did not find any significant differences between the treatment groups in need of physiotherapy or surgery and the patients receiving sickness benefit. We expected fear avoidance belief scores to be low at baseline and to fall during follow-up, because patients were informed about the favourable prognosis of the lumbar radiculopathy and were repeatedly encouraged to stay active.

\section{Comparison with existing literature}

There is conflicting evidence on whether epidural steroid injections are efficacious, ${ }^{61-63}$ and if so, what volume, composition, or concentration of injection is best. ${ }^{29} 5364-70$ Two randomised studies found that transforaminal steroid injections, which deposit the medication directly over the affected nerve roots, are more effective than caudal epidural steroid injections in the short term. ${ }^{6371} \mathrm{We}$ did not address this issue in our study. Four randomised placebo controlled trials published between 1971 and 2009 with at least 12 months' follow-up, including between 23 and 183 participants, found no long term effect of caudal epidural steroid injections. ${ }^{29} 30323372$ One study showed a positive effect of caudal epidural steroid injection. ${ }^{72}$ However, the reported effect size (change in Oswestry disability index score of 8.1 points) was smaller than what is considered to be the minimal clinically significant difference. ${ }^{43}$

High volumes of epidural solutions have been thought to clear or dilute locally concentrated chemical irritants around the spinal nerve roots. ${ }^{29} 72$ In our study, the effect of a high volume, caudal epidural saline injection did not differ from a sham injection. Our results suggest that the effect attributed to isotonic saline probably reflects the spontaneous, natural course of lumbar radiculopathy. ${ }^{73}$

\section{Strengths and limitations}

This multicentre randomised controlled study was designed to determine whether high volume, epidural saline injections alone or epidural saline injections in combination with epidural steroid could benefit patients with longstanding radiculopathy. The study population was homogeneous with low psychosocial strain. We carefully selected patients on the basis of clinical criteria and not on strict magnetic resonance imaging findings. This method accords with how epidural steroid injections are used in daily clinical practice, improving the external validity of our study. We used the caudal epidural injection technique with ultrasound guiding to improve the precision. However, we did not use contrast to visualise where the medication spread. The use of large volumes $(30 \mathrm{~mL})$ for the epidural injections ensured sufficient spread of the medication, reducing the need for radiography during the injection procedure.

Our power calculation required inclusion of 41 patients in each group to detect a 10 point between group difference for the primary outcome measure. We did not reach this goal because of rapid improvement in 17 patients between inclusion and randomisation. Therefore, the study was slightly underpowered, with four patients missing from the epidural steroid group, two from the epidural saline group, and one from the sham group. However, the study showed no trend towards any group difference after 12 months. We therefore consider it highly unlikely that a larger study population would have affected the results. Furthermore, the patients in our study had longlasting symptoms of radiculopathy (range 26-57 weeks), and our results might not be as relevant for patients with radiculopathy of shorter duration.

Low efficacy, under-dosage, and a dilution effect due to the high volumes injected could have influenced the effect of the caudal epidural steroid injection in our study. The most commonly used steroids for epidural injections are triamcinolone acetonide, betamethasone, and methylprednisolone. One study compared triamcinolone and betamethasone and favoured triamcinolone. ${ }^{74}$ When given in equivalent doses, the efficacy of these three steroids is generally considered to be comparable. ${ }^{22}$ In one study, researchers also used triamcinolone to compare the effect of lumbar epidural steroid injection with placebo. ${ }^{22}$ They gave three $80 \mathrm{mg}$ injections over nine weeks (total dose $240 \mathrm{mg}$ ), whereas we used two $40 \mathrm{mg}$ injections over two weeks (total dose $80 \mathrm{mg}$ ). The observed effects from the previous study did not differ from our results. It is therefore unlikely that we could have improved the treatment effects by using another steroid, or by increasing the dose of triamcinolone. ${ }^{75}$

We thank Jan Inge Letto, Anne Sofie Broback, Dag Grindheim, Robert Kouwenhoven, Fredrik Granviken, Franz Hintringer, Svetlana Rasic, Helge Hartman, Sigrun Randen, and Einar Vegå for doing the assessments; Olaf Sivertsen, Just Thoner, Jørgen Hansen, Gunnar Engesnes, Niels Becker, and Tarjei Rygnestad for doing the epidural 


\section{What is already known on this topic}

Clinical studies indicate that epidural steroid and saline injections might reduce pain due to acute lumbar radiculopathy in the short term, but the middle term and long term effects are unknown

\section{What this study adds}

Neither caudal epidural steroid injections nor caudal epidural saline injections are effective for chronic lumbar radiculopathy and are not recommended as an adjunct to recovery in patients whose symptoms have extended beyond 12 weeks

injections; the Clinical Research Centre at the University Hospital of North Norway, Bjørn Odvar Eriksen, Inger Sperstad, May Greta Pedersen, Sameline Grimsgaard, Dag Grønvoll, Aslaug Jakobsen, Rolf Salvesen, Dagfinn Thorsvik, Tormod Hagen, Bjørn Skogstad, Therese Norberg Hanvold, and all the patients who participated in this study; and Bjørn Aske of Medinor Norway for lending us the Honda Ultrasound machines.

Contributors: TIversen contributed to the study design, data collection, data analysis, interpretation, and writing of the manuscript. TS, $\varnothing \mathrm{N}$, TIngebrigtsen, TW, AA, and BR contributed to the study design, data analysis, interpretation, and writing of the manuscript. TH contributed to the study design. JT contributed to data analysis and interpretation. Data verification was undertaken by the Clinical Research Centre at the University Hospital of North Norway.

Funding: The study was supported by the North Norway Regional Health Authority and Health Region Nord-Trøndelag, Norway.

Competing interests: All authors have completed the ICMJE uniform disclosure form at www.icmje.org/coi_disclosure.pdf (available on request from the corresponding author) and declare: this study was supported by the North Norway Regional Health Authority and Health Region Nord-Trøndelag; no financial relationships with any organisations that might have an interest in the submitted work in the previous 3 years; no other relationships or activities that could appear to have influenced the submitted work.

Ethical approval: The study protocol was approved by the ethics committee for Medical Research Region 5 Norway.

Data sharing: Technical appendix, statistical code, and dataset are available from the corresponding author.

1 Price C, Arden N, Coglan L, Rogers P. Cost-effectiveness and safety of epidural steroids in the management of sciatica. Health Technol Assess 2005;9:1-58,iii.

Waddell G. The back pain revolution. 2nd ed. Churchill Livingstone, 2004.

3 Fairbank JC. Sciatic: an archaic term. BMJ 2007;335:112.

4 Koes BW, van Tulder MW, Peul WC. Diagnosis and treatment of sciatica. BMJ 2007;334:1313-7.

5 Heliovaara M, Impivaara O, Sievers K, Melkas T, Kneckt P, Korpi J, et al. Lumbar disc syndrome in Finland. J Epidemiol Community Health 1987:41:251-8.

6 Konstantinou K, Dunn KM. Sciatica: review of epidemiological studies and prevalence estimates. Spine (Phila Pa 1976) 2008;33:2464-72.

7 Karppinen J, Ohinmaa A, Malmivaara A, et al. Cost effectiveness of periradicular infiltration for sciatica: subgroup analysis of a randomized controlled trial. Spine (Phila Pa 1976) 2001;26:2587-95

8 Vad VB, Bhat AL, Lutz GE, Cammisa F. Transforaminal epidural steroid injections in lumbosacral radiculopathy: a prospective randomized study. Spine (Phila Pa 1976) 2002;27:11-6

9 Bush K, Cowan N, Katz DE, Gishen P. The natural history of sciatica associated with disc pathology. A prospective study with clinical and independent radiologic follow-up. Spine (Phila Pa 1976) 1992;17:1205-12.

10 Weber $\mathrm{H}, \mathrm{Holme}$ I, Amlie E. The natural course of acute sciatica with nerve root symptoms in a double-blind placebo-controlled trial evaluating the effect of piroxicam. Spine (Phila Pa 1976) 1993;18:1433-8.

11 Goebert HW Jr, Jallo SJ, Gardner WJ, Wasmuth CE. Painful radiculopathy treated with epidural injections of procaine and hydrocortisone acetate: results in 113 patients. Anesth Analg 1961;40:130-4

12 Rydevik B, Brown MD, Lundborg G. Pathoanatomy and pathophysiology of nerve root compression. Spine (Phila Pa 1976) 1984:9:7-15.

13 Goupille P, Jayson MI, Valat JP, Freemont AJ. The role of inflammation in disk herniation-associated radiculopathy. Semin Arthritis Rheum 1998;28:60-71.

14 Autio RA, Karppinen J, Kurunlahti M, Haapea M, Vanharanta H, Tervonen O. Effect of periradicular methylprednisolone on spontaneous resorption of intervertebral disc herniations. Spine (Phila Pa 1976) 2004:29:1601-7.

15 Muramoto T, Atsuta Y, Iwahara T, Sato M, Takemitsu Y. The action of prostaglandin E2 and triamcinolone acetonide on the firing activity of lumbar nerve roots. Int Orthop 1997;21:172-5.
16 Nygaard OP, Mellgren SI, Osterud B. The inflammatory properties of contained and noncontained lumbar disc herniation. Spine (Phila Pa 1976) 1997;22:2484-8.

17 Chou R, Loeser JD, Owens DK, Rosenquist RW, Atlas SJ, Baisden J, et al. Interventional therapies, surgery, and interdisciplinary rehabilitation for low back pain: an evidence-based clinical practice guideline from the American Pain Society. Spine (Phila Pa 1976) 2009;34:1066-77.

18 Koes BW, Scholten RJ, Mens JM, Bouter LM. Efficacy of epidural steroid injections for low-back pain and sciatica: a systematic review of randomized clinical trials. Pain 1995:63:279-88.

19 Watts RW, Silagy CA. A meta-analysis on the efficacy of epidural corticosteroids in the treatment of sciatica. Anaesth Intensive Care 1995;23:564-9.

20 Luijsterburg PA, Verhagen AP, Ostelo RW, van Os TA, Peul WC, Koes BW. Effectiveness of conservative treatments for the lumbosacral radicular syndrome: a systematic review. Eur Spine J 2007;16:881-99.

21 Conn A, Buenaventura RM, Datta S, Abdi S, Diwan S. Systematic review of caudal epidural injections in the management of chronic low back pain. Pain Physician 2009;12:109-35.

22 Arden NK, Price C, Reading I, Stubbing J, Hazelgrove J, Dunne C, et al. A multicentre randomized controlled trial of epidural corticosteroid injections for sciatica: the WEST study. Rheumatology (Oxford) 2005;44:1399-406.

23 Wilson-MacDonald J, Burt G, Griffin D, Glynn C. Epidural steroid injection for nerve root compression. A randomised, controlled trial. J Bone Joint Surg Br 2005;87:352-55.

24 Beliveau P. A comparison between epidural anaesthesia with and without corticosteroid in the treatment of sciatica. Rheumatol Phys Med 1971;11:40-3.

25 Cuckler JM, Bernini PA, Wiesel SW, Booth RE Jr, Rothman RH, Pickens GT. The use of epidural steroids in the treatment of lumbar radicular pain. A prospective, randomized, double-blind study. J Bone Joint Surg Am 1985;67:63-6.

26 Carette S, Leclaire R, Marcoux S, Morin F, Blaise GA, St-Pierre A, et al. Epidura corticosteroid injections for sciatica due to herniated nucleus pulposus. N Engl J Med 1997;336:1634-40

$27 \mathrm{Ng}$ L, Chaudhary N, Sell P. The efficacy of corticosteroids in periradicular infiltration for chronic radicular pain: a randomized, double-blind, controlled trial. Spine (Phila Pa 1976) 2005;30:857-62.

28 Karppinen J, Malmivaara A, Kurunlahti M, Kyllonen E, Pienimaki T, Nieminen P, et al. Periradicular infiltration for sciatica: a randomized controlled trial. Spine (Phila Pa 1976) 2001:26:1059-7.

29 Bush K, Hillier S. A controlled study of caudal epidural injections of triamcinolone plus procaine for the management of intractable sciatica. Spine (Phila Pa 1976) 1991;16:572-5.

30 Breivik H, Hesla PE, Molnar I. Treatment of chronic low back pain and sciatica: comparison of caudal epidural injections of bupivacaine and methylprednisolone with bupivacaine followed by saline. Adv Pain Res Ther 1976;1:927-32.

31 Ridley MG, Kingsley GH, Gibson T, Grahame R. Outpatient lumbar epidural corticosteroid injection in the management of sciatica. Br J Rheumatol 1988;27:295-9.

32 Mathews JA, Mills SB, Jenkins VM, Grimes SM, Morkel MJ, Mathews W, et al. Back pain and sciatica: controlled trials of manipulation, traction, sclerosant and epidural injections. Br J Rheumatol 1987;26:416-23.

33 Manchikanti L, Singh V, Cash KA, Pampati V, Damron KS, Boswell MV. Preliminary results of a randomized, equivalence trial of fluoroscopic caudal epidural injections in managing chronic low back pain: Part 2-disc herniation and radiculitis. Pain Physician 2008;11:801-15.

34 Rabinovitch DL, Peliowski A, Furlan AD. Influence of lumbar epidural injection volume on pain relief for radicular leg pain and/or low back pain. Spine J 2009;9:509-17.

35 Buttermann GR. Treatment of lumbar disc herniation: epidural steroid injection compared with discectomy. A prospective, randomized study. J Bone Joint Surg Am 2004;86-A:670-9.

36 Komori H, Okawa A, Haro H, Shinomiya Ki K. Factors predicting the prognosis of lumbar radiculopathy due to disc herniation. J Orthop Sci 2002;7:56-61.

37 Saal JA, Saal JS, Herzog RJ. The natural history of lumbar intervertebral disc extrusions treated nonoperatively. Spine (Phila Pa 1976) 1990;15:683-6.

38 Friedly J, Chan L, Deyo R. Increases in lumbosacral injections in the Medicare population: 1994 to 2001. Spine (Phila Pa 1976) 2007;32:1754-60.

39 Grotle M, Brox Jl, Vollestad NK. Reliability, validity and responsiveness of the fear-avoidance beliefs questionnaire: methodological aspects of the Norwegian version. J Rehabil Med 2006;38:346-53.

40 Hagen EM, Odelien KH, Lie SA, Eriksen HR. Adding a physical exercise programme to brief intervention for low back pain patients did not increase return to work. Scand J Public Health 2010;38:731-8.

41 Storheim K, Brox JI, Holm I, Kolle AK, Bo K. Intensive group training versus cognitive intervention in sub-acute low back pain: short-term results of a single-blind randomized controlled trial. J Rehabil Med 2003;35:132-40.

42 Skouen JS, Grasdal AL, Haldorsen EM, Ursin H. Relative cost-effectiveness of extensive and light multidisciplinary treatment programs versus treatment as usual for patients with chronic low back pain on long-term sick leave: randomized controlled study. Spine (Phila Pa 1976) 2002;27:901-9.

43 Brox Jl, Sorensen R, Friis A, Nygaard O, Indahl A, Keller A, et al. Randomized clinica trial of lumbar instrumented fusion and cognitive intervention and exercises in patients with chronic low back pain and disc degeneration. Spine (Phila Pa 1976) 2003;28:1913-21.

44 Laerum E, Indahl A, Skouen JS. What is "the good back-consultation"? A combined qualitative and quantitative study of chronic low back pain patients' interaction with and perceptions of consultations with specialists. J Rehabil Med 2006;38:255-62. 
45 Grotle M, Brox JI, Vollestad NK. Cross-cultural adaptation of the Norwegian versions of the Roland-Morris Disability Questionnaire and the Oswestry Disability Index. J Rehabil Med 2003;35:241-7.

46 Roland M, Fairbank J. The Roland-Morris Disability Questionnaire and the Oswestry Disability Questionnaire. Spine (Phila Pa 1976) 2000;25:3115-24.

47 Hagg O, Fritzell P, Nordwall A. The clinical importance of changes in outcome scores after treatment for chronic low back pain. Eur Spine J 2003;12:12-20.

48 EuroQol-a new facility for the measurement of health-related quality of life. The EuroQol Group. Health Policy 1990;16:199-208.

49 Dolan P. Modeling valuations for EuroQol health states. Med Care 1997;35:1095-108.

50 Solberg TK, Olsen JA, Ingebrigtsen T, Hofoss D, Nygaard OP. Health-related quality of life assessment by the EuroQol-5D can provide cost-utility data in the field of low-back surgery. Eur Spine J 2005;14:1000-7.

51 Giraudeau B, Rozenberg S, Valat JP. Assessment of the clinically relevant change in pain for patients with sciatica. Ann Rheum Dis 2004;63:1180-1.

52 Peul WC, van den Hout WB, Brand R, Thomeer RT, Koes BW; Leiden-The Hague Spine Intervention Prognostic Study Group. Prolonged conservative care versus early surgery in patients with sciatica caused by lumbar disc herniation: two year results of a randomised controlled trial. BMJ 2008;336:1355-8.

53 Stitz MY, Sommer HM. Accuracy of blind versus fluoroscopically guided caudal epidural injection. Spine (Phila Pa 1976) 1999;24:1371-6.

54 The Royal College of Anaesthetists. Recommendations on the use of epidural injections for the treatment of back pain and leg pain of spinal origin. Royal College of Anaesthetists, 2002:695-7.

55 Chen CP, Tang SF, Hsu TC, Tsai WC, Kiu HP, Chen MJ, et al. Ultrasound guidance in caudal epidural needle placement. Anesthesiology 2004;101:181-4.

56 Chen CP, Wong AM, Hsu CC, Tsai WC, Chang CN, Lin SC, et al. Ultrasound as a screening tool for proceeding with caudal epidural injections. Arch Phys Med Rehabil 2010;91:358-63.

57 Klocke R, Jenkinson T, Glew D. Sonographically guided caudal epidural steroid injections. J Ultrasound Med 2003;22:1229-32.

58 Cohen SP, Bogduk N, Dragovich A, Buckenmaier CC 3rd, Griffith SM, Kurihara C, et al. Randomized, double-blind, placebo-controlled, dose-response, and preclinical safety study of transforaminal epidural etanercept for the treatment of sciatica. Anesthesiology 2009;110:1116-26

59 Twisk JW, de Vente W. The analysis of randomised controlled trial data with more than one follow-up measurement. A comparison between different approaches. Eur J Epidemio 2008;23:655-60.

60 Copay AG, Glassman SD, Subach BR. Minimum clinically important difference in lumbar spine surgery patients: a choice of methods using the Oswestry Disability Index, Medical Outcomes Study questionnaire Short Form 36, and pain scales. Spine J 2008;8:968-74.

61 Mendoza-Lattes S, Weiss A, Found E, Zimmerman B, Gao Y. Comparable effectiveness of caudal vs trans-foraminal epidural steroid injections. lowa Orthop J 2009;29:91-6.

62 Dashfield AK, Taylor MB, Cleaver JS, Farrow D. Comparison of caudal steroid epidural with targeted steroid placement during spinal endoscopy for chronic sciatica: a prospective, randomized, double-blind trial. Br J Anaesth 2005;94:514-9.
63 Ackerman WE III, Ahmad M. The efficacy of lumbar epidural steroid injections in patients with lumbar disc herniations. Anesth Analg 2007:104:1217-22.

64 Nelemans PJ, de Bie RA, de Vet HC, Sturmans F. Injection therapy for subacute and chronic benign low back pain. Cochrane Database Syst Rev 2000;2:CD001824.

65 Novak S, Nemeth WC. The basis for recommending repeating epidural steroid injections for radicular low back pain: a literature review. Arch Phys Med Rehabil 2008;89:543-52.

66 Nelson DA, Landau WM. Intraspinal steroids: history, efficacy, accidentality, and controversy with review of United States Food and Drug Administration reports. J Neurol Neurosurg Psychiatry 2001;70:433-43.

67 Sethee J, Rathmell JP. Epidural steroid injections are useful for the treatment of low back pain and radicular symptoms: pro. Curr Pain Headache Rep 2009;13:31-4.

68 Rathmell JP. The argument for use of epidural steroid injections in management of acute radicular pain. Perm J 2007;11:54-6.

69 Armon C, Argoff CE, Samuels J, Backonia MM; Therapeutics and Technology Assessment Subcommittee of the American Academy of Neurology. Assessment: use of epidural steroid injections to treat radicular lumbosacral pain: report of the Therapeutics and Technology Assessment Subcommittee of the American Academy of Neurology. Neurology 2007;68:723-9.

70 Hopayian $\mathrm{K}$. The need for caution in interpreting high quality systematic reviews. BMJ 2001;323:681-4.

71 Ghahreman A, Ferch R, Bogduk N. The efficacy of transforaminal injection of steroids for the treatment of lumbar radicular pain. Pain Med 2010;11:1149-68.

72 Sayegh FE, Kenanidis EI, Papavasiliou KA, Potoupnis ME, Kirkos JM, Kapetanos GA, et al. Efficacy of steroid and nonsteroid caudal epidural injections for low back pain and sciatica: a prospective, randomized, double-blind clinical trial. Spine (Phila Pa 1976) 2009;34:1441-7.

73 Weinstein JN, Tosteson TD, Lurie JD, Tosteson AN, Hanscom B, Skinner JS, et al. Surgical vs nonoperative treatment for lumbar disk herniation: the Spine Patient Outcomes Research Trial (SPORT): a randomized trial. JAMA 2006;296:2441-50.

74 Stanczak J, Blankenbaker DG, De Smet AA, Fine J. Efficacy of epidural injections of Kenalog and Celestone in the treatment of lower back pain. AJR Am J Roentgenol 2003;181:1255-8.

75 Owlia MB, Salimzadeh A, Alishiri G, Haghighi A. Comparison of two doses of corticosteroid in epidural steroid injection for lumbar radicular pain. Singapore Med J 2007;48:241-5.

Accepted: 17 July 2011

\section{Cite this as: BMJ 2011:343:d5278}

This is an open-access article distributed under the terms of the Creative Commons Attribution Non-commercial License, which permits use, distribution, and reproduction in any medium, provided the original work is properly cited, the use is non commercial and is otherwise in compliance with the license. See: http://creativecommons.org/licenses/by$\mathrm{nc} / 2.0 /$ and http://creativecommons.org/licenses/by-nc/2.0/legalcode. 


\section{Tables}

Table 1 Number (\%) of patients at follow-up, by randomisation group

Follow-up Sham group $(n=40)$ Caudal epidural saline group $(n=39)$ Caudal epidural steroid group $(n=37)$ Total no $(n=116)$

\begin{tabular}{lllll}
6 weeks & $37(93)$ & $35(90)$ & $37(100)$ & $109(94)$ \\
\hline 12 weeks & $36(90)$ & $35(90)$ & $34(92)$ & $105(91)$ \\
\hline 52 weeks & $32(80)$ & $33(85)$ & $34(92)$ & $99(85)$
\end{tabular}


Table 2| Number of patients at follow-up, by randomisation group

Follow-up hospital/week Sham group Caudal epidural saline group Caudal epidural steroid group Total no University Hospital of North Norway

\begin{tabular}{|c|c|c|c|c|}
\hline 6 & 15 & 10 & 13 & 38 \\
\hline 12 & 14 & 10 & 12 & 36 \\
\hline 52 & 13 & 9 & 12 & 34 \\
\hline \multicolumn{5}{|c|}{ Nordland Hospital } \\
\hline 6 & 8 & 10 & 8 & 26 \\
\hline 12 & 6 & 6 & 6 & 18 \\
\hline 52 & 6 & 6 & 5 & 17 \\
\hline \multicolumn{5}{|c|}{ Levanger Hospital } \\
\hline 6 & 8 & 10 & 8 & 26 \\
\hline 12 & 7 & 10 & 6 & 23 \\
\hline 52 & 6 & 10 & 7 & 23 \\
\hline \multicolumn{5}{|c|}{ St Olavs University Hospital } \\
\hline 6 & 5 & 7 & 7 & 19 \\
\hline 12 & 5 & 6 & 7 & 19 \\
\hline 52 & 5 & 5 & 7 & 17 \\
\hline \multicolumn{5}{|c|}{ Buskerud Hospital } \\
\hline 6 & 3 & 3 & 3 & 9 \\
\hline 12 & 4 & 3 & 3 & 13 \\
\hline 52 & 2 & 3 & 3 & 5 \\
\hline
\end{tabular}




\begin{tabular}{|c|c|c|c|}
\hline & Sham group $(n=40)$ & $\begin{array}{l}\text { Caudal epidural saline group } \\
\qquad(n=39)\end{array}$ & $\begin{array}{l}\text { Caudal epidural steroid group } \\
\qquad(n=37)\end{array}$ \\
\hline Mean (SD) age (years) & $42.8(9.2)$ & $42.8(11.6)$ & $40.1(10.0)$ \\
\hline Male sex & $24(60)$ & $24(62)$ & $20(54)$ \\
\hline Mean (SD) body mass index $\left(\mathrm{kg} / \mathrm{m}^{2}\right)$ & $26.0(3.3)$ & $26.1(3.6)$ & $26.7(4.5)$ \\
\hline Physically demanding work & $19(47)$ & $18(46)$ & $21(57)$ \\
\hline Received sickness benefit* & $22(55)$ & $26(67)$ & $25(68)$ \\
\hline Mean (SD) duration of sick leave (weeks) & $14.0(32.8)$ & $21.3(32.7)$ & $20.1(37.6)$ \\
\hline Mean (SD) duration of leg pain (weeks) & $26.7(22.4)$ & $57.1(158.0)$ & $42.5(62.6)$ \\
\hline Mean (SD) duration of back pain (weeks) & $46.6(86.3)$ & $63.1(157.8)$ & $50.4(64.3)$ \\
\hline \multicolumn{4}{|l|}{ Use of analgesics } \\
\hline Paracetamol & $13(33)$ & $9(23)$ & $11(30)$ \\
\hline NSAID & $6(15)$ & $4(10)$ & $10(27)$ \\
\hline Morphine & $6(15)$ & $7(18)$ & $9(24)$ \\
\hline Positive straight leg raising test $†$ & $21(53)$ & $23(59)$ & $18(49)$ \\
\hline Dermatomal sensory loss & $31(78)$ & $23(59)$ & $29(78)$ \\
\hline Dermatomal muscle weakness & $31(78)$ & $31(80)$ & $32(87)$ \\
\hline Knee tendon reflex difference & $6(15)$ & $9(23)$ & $6(16)$ \\
\hline Ankle tendon reflex differenceł & $13(33)$ & $24(62)$ & $10(27)$ \\
\hline \multicolumn{4}{|c|}{ Clinically suspected level of lumbar radiculopathy } \\
\hline L2-L3 & - & - & $1(3)$ \\
\hline L3-L4 & $3(8)$ & $2(5)$ & $2(5)$ \\
\hline L4-L5 & $12(30)$ & $11(28)$ & $14(38)$ \\
\hline L5-S1 & $25(63)$ & $26(67)$ & $20(54)$ \\
\hline \multicolumn{4}{|l|}{ MRI or CT findings } \\
\hline Normal & - & $1(3)$ & - \\
\hline Disc protrusion & $1(3)$ & - & - \\
\hline Disc herniation & $24(60)$ & $23(59)$ & $26(70)$ \\
\hline Disc sequestration & $14(35)$ & $14(36)$ & $11(30)$ \\
\hline Recess stenosis & $1(3)$ & $1(3)$ & - \\
\hline Mean (95\% CI) FABQ work & 21.6 (17.9 to 25.3$)$ & 25.0 (21.9 to 28.1$)$ & 23.5 (20.5 to 26.5$)$ \\
\hline Mean $(95 \% \mathrm{Cl}) \mathrm{FABQ}$ physical activity & $13.0(11.3$ to 14.7$)$ & $13.5(12.1$ to 14.9$)$ & $11.9(10.2$ to 13.6$)$ \\
\hline Mean $(95 \% \mathrm{Cl})$ Oswestry disability index & 26.3 (22.0 to 30.6$)$ & 31.4 (26.9 to 35.9$)$ & 32.5 (28.6 to 36.4$)$ \\
\hline Mean $(95 \% \mathrm{Cl})$ EQ5D & $0.54(0.47$ to 0.56$)$ & $0.46(0.35$ to 0.56$)$ & $0.54(0.45$ to 0.62$)$ \\
\hline Mean $(95 \% \mathrm{Cl})$ VAS leg pain & 48.3 (39.6 to 56.9$)$ & 53.5 (45.6 to 61.3$)$ & 50.1 (42.5 to 57.7$)$ \\
\hline Mean $(95 \% \mathrm{Cl})$ VAS back pain & 46.3 (39.2 to 54.1$)$ & 49.6 (40.3 to 58.2$)$ & 46.8 (39.0 to 54.6$)$ \\
\hline \multicolumn{4}{|c|}{$\begin{array}{l}\text { Data are number }(\%) \text { unless stated otherwise. } S D=\text { standard deviation; } C l=\text { confidence intervals; } N S A I D=\text { non-steroidal anti-inflammatory drug; } M R I=\text { magnetic } \\
\text { resonance imaging; } C T=\text { computer tomography; } F A B Q=\text { fear avoidance beliefs questionnaire; } E Q 5 D=E \text { uropean quality of life measure; } V A S=v i s u a l \text { analogue scale. } \\
\text { *On full or partial sick leave, government funded rehabilitation, or disability pension. } \\
\text { †When radiating leg pain }>60^{\circ} \text { elevated leg. } \\
\ddagger P=0.004 \text { difference. }\end{array}$} \\
\hline
\end{tabular}


Table 4| Estimated differences in Oswestry disability index score between epidural injection groups and sham group at follow-up

Difference (95\% confidence intervals) at follow-up

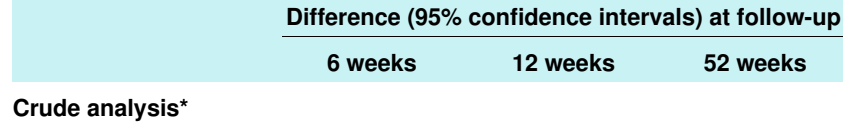

Epidural saline injection $-0.5(-6.3$ to 5.4$) \quad 1.4(-4.5$ to 7.2$)-1.9(-8.0$ to 4.3$)$

Epidural steroid injection -2.9 (-8.7 to 3.0$) \quad 4.0$ (-1.9 to 9.9$) \quad 1.9$ (-4.2 to 8.0$)$

Adjusted analysis $†$

Epidural saline injection -0.6 (-6.6 to 5.4$) \quad 1.5(-4.5$ to 7.5$) \quad-2.6$ (-8.9 to 3.6$)$

Epidural steroid injection $-3.2(-9.1$ to 2.7$) \quad 3.7(-2.3$ to 9.7$) \quad 1.7(-4.5$ to 7.8$)$

Data based on mixed model analysis with sham group as reference.

${ }^{*}$ Analysis adjusted for baseline values.

†Analysis adjusted for duration of leg pain, back pain, and sick leave. 


\begin{tabular}{|c|c|c|c|}
\hline \multirow{2}{*}{ Table 5| } & \multicolumn{3}{|c|}{ Difference ( $95 \%$ confidence intervals) at follow-up } \\
\hline & 6 weeks & 12 weeks & 52 weeks \\
\hline \multicolumn{4}{|l|}{ Leg pain } \\
\hline \multicolumn{4}{|l|}{ Crude analysis ${ }^{*}$} \\
\hline Epidural saline injection & $3.2(-9.1$ to 15.5$)$ & $2.5(-9.6$ to 14.6$)$ & $3.1(-9.6$ to 15.8$)$ \\
\hline Epidural steroid injection & $-1.3(-13.3$ to 10.7$)$ & $11.2(-1.0$ to 23.4$)$ & $-0.2(-12.9$ to 12.5$)$ \\
\hline \multicolumn{4}{|l|}{ Adjusted analysis $\dagger$} \\
\hline Epidural saline injection & $2.7(-9.8$ to 15.2$)$ & $1.7(-10.7$ to 14.0$)$ & $0.5(-12.4$ to 13.4$)$ \\
\hline Epidural steroid injection & $-2.6(-14.6$ to 9.4$)$ & $10.0(-2.2$ to 22.3$)$ & $-1.4(-14.1$ to 11.4$)$ \\
\hline \multicolumn{4}{|l|}{ Low back pain } \\
\hline \multicolumn{4}{|l|}{ Crude analysis $^{*}$} \\
\hline Epidural saline injection & $-5.0(-16.7$ to 6.7$)$ & $-7.8(-19.3$ to 3.8$)$ & $-2.0(-14.3$ to 10.2$)$ \\
\hline Epidural steroid injection & $-4.8(-16.2$ to 6.6$)$ & $6.6(-5.0$ to 18.2$)$ & $0.0(-12.1$ to 12.2$)$ \\
\hline \multicolumn{4}{|l|}{ Adjusted analysis $\dagger$} \\
\hline Epidural saline injection & $-6.9(-18.8$ to 5.1$)$ & $-9.3(-21.2$ to 2.5$)$ & $-4.1(-16.5$ to 8.4$)$ \\
\hline Epidural steroid injection & $-6.4(-17.9$ to 5.1$)$ & $5.1(-6.5$ to 16.8$)$ & $-1.4(-13.6$ to 10.8$)$ \\
\hline \multicolumn{4}{|c|}{ European quality of life measure } \\
\hline \multicolumn{4}{|l|}{ Crude analysis $^{*}$} \\
\hline Epidural saline injection & $-0.02(-0.13$ to 0.09$)$ & $-0.05(-0.17$ to 0.06$)$ & $-0.01(-0.12$ to 0.11$)$ \\
\hline Epidural steroid injection & $-0.05(-0.16$ to 0.06$)$ & $-0.12(-0.23$ to -0.00$)$ & $-0.05(-0.17$ to 0.06$)$ \\
\hline \multicolumn{4}{|c|}{ Adjusted analysis $\dagger$} \\
\hline Epidural saline injection & $-0.01(-0.13$ to 0.10$)$ & $-0.05(-0.16$ to 0.06$)$ & $0.01(-1.06$ to 0.13$)$ \\
\hline Epidural steroid injection & $-0.04(-0.15$ to 0.07$)$ & $-0.11(0.22$ to 0.00$)$ & $-0.05(-1.62$ to 0.07$)$ \\
\hline $\begin{array}{l}\text { Data based on mixed mode } \\
\text { *Analysis adjusted for base } \\
\text { †Analysis adjusted for dura }\end{array}$ & $\begin{array}{l}\text { lel analysis with sham } g \\
\text { eline values. } \\
\text { ation of leg pain, back } \mathrm{p}\end{array}$ & $\begin{array}{l}\text { group as reference. } \\
\text { oain, and sick leave. }\end{array}$ & \\
\hline
\end{tabular}


Table 6 | Estimated differences in fear avoidance beliefs between epidural injection groups and sham group at follow-up

\begin{tabular}{|c|c|c|c|}
\hline \multirow[b]{2}{*}{ Analysis } & \multicolumn{3}{|c|}{ Difference ( $95 \%$ confidence intervals) at follow-up } \\
\hline & 6 weeks & 12 weeks & 52 weeks \\
\hline \multicolumn{4}{|c|}{ FABQ regarding physical activity } \\
\hline Epidural saline injection & $-0.24(-2.69$ to 2.21$)$ & $-2.10(-4.66$ to -4.5$)$ & $-0.24(-2.69$ to 2.21$)$ \\
\hline Epidural steroid injection & $0.60(-1.84$ to 3.03$)$ & $-0.67(-3.22$ to 1.87$)$ & $0.60(-1.84$ to 3.03$)$ \\
\hline \multicolumn{4}{|l|}{ FABQ regarding work } \\
\hline Epidural saline injection & $0.72(-3.10$ to 4.55$)$ & $0.47(-3.51$ to 4.44$)$ & $0.72(-3.10$ to 4.55$)$ \\
\hline Epidural steroid injection & $2.31(-1.48$ to 6.11$)$ & $2.40(-1.55$ to 6.34$)$ & $2.31(-1.48$ to 6.11$)$ \\
\hline
\end{tabular}

$\mathrm{FABQ}=$ fear avoidance beliefs questionnaire. Data based on mixed model analysis with sham group as reference. 
Table 7| Use of pain relief medication at 6 week follow-up

Drug Sham group Caudal epidural saline group Caudal epidural steroid group

$\begin{array}{llll}\text { Paracetamol } & 9(24.3) & 7(20.0) & 9(24.3)\end{array}$

$\begin{array}{llll}\text { Non-steroidal anti-inflammatory drugs } & 2(5.4) & 4(11.4) & 6(16.2)\end{array}$

Morphine

$4(10.8)$

$6(17.1)$

$3(8.1)$

Data are number (\%) of patients. 


\section{Figures}

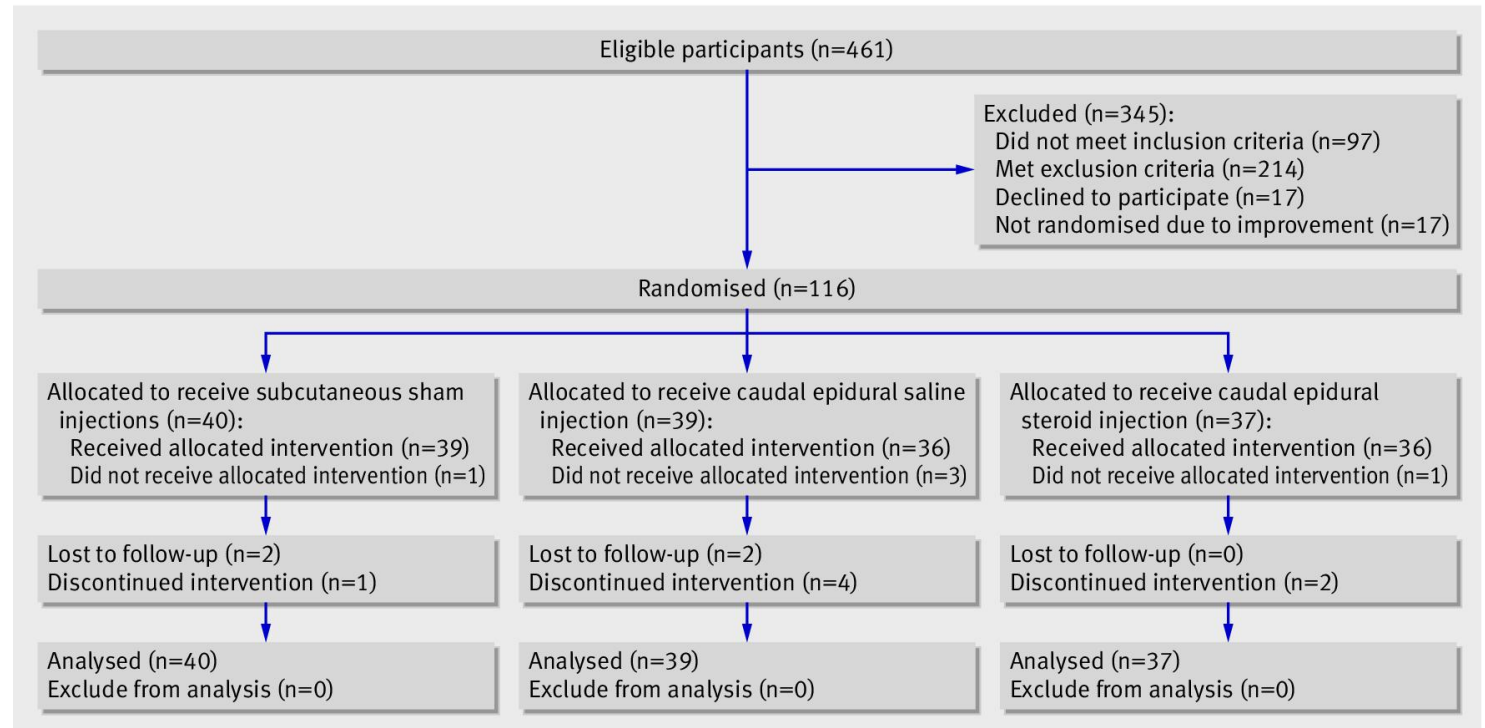

Fig 1 Flow of participants in study

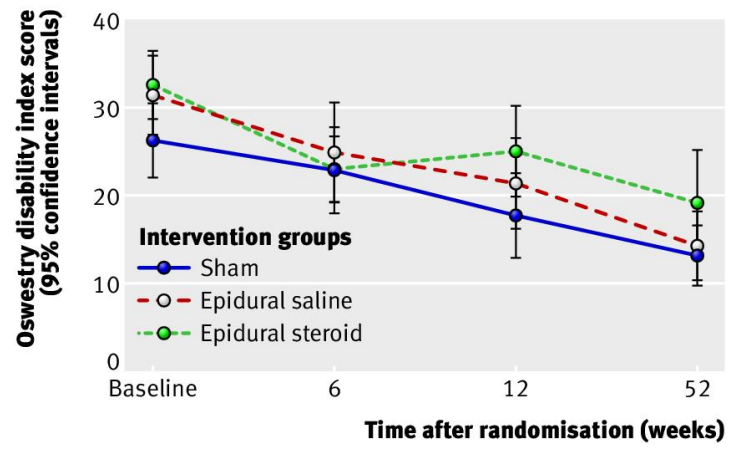

Fig 2 Mean Oswestry disability index score at follow-up

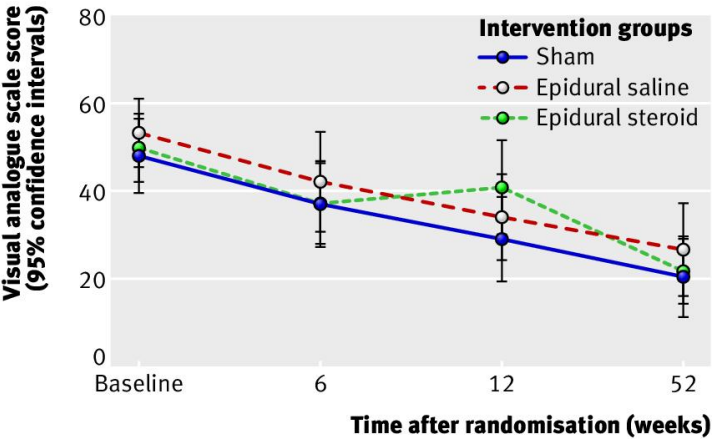

Fig 3 Mean visual analogue scale score for leg pain at follow-up 


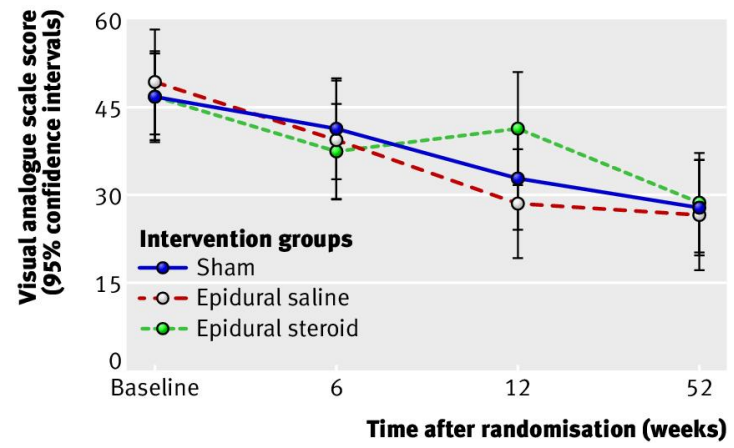

Fig 4 Mean visual analogue scale score for back pain at follow-up

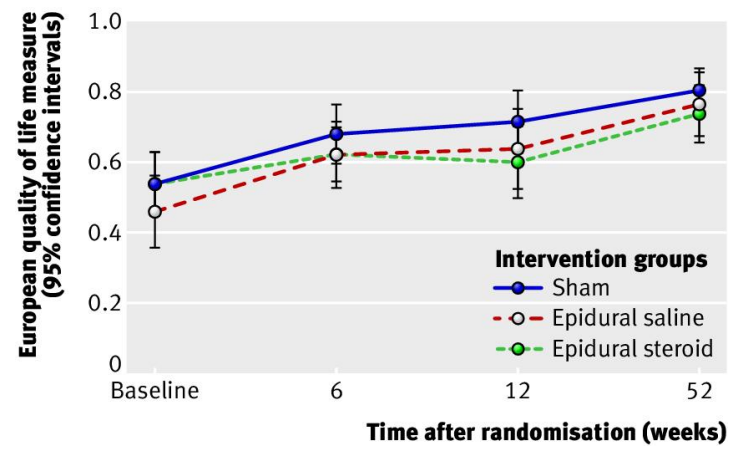

Fig 5 Repeated measurement of mean score for European quality of life measure 